УДК 81’42:004.738.5

ББК 81.1

\section{Б.Г. Вульфович}

\section{СТИЛИСТИЧЕСКИЕ ОСОБЕННОСТИ ПОЛИТИЧЕСКОГО ИНТЕРНЕТ-ДИСКУРСА (на материале комментариев к постам Терезы Мэй в социальной сети "Twitter»)}

Благодаря Интернету современный политический дискурс вышел на новый уровень - двусторонний. Он проявляется в том, что можно оставлять комментарий к любому посту на странице, при этом велика вероятность, что адресат не просто увидит его и прочтёт, но и ответит. Поскольку комментарий является непосредственным речевым актом индивида, он может быть рассмотрен с точки зрения стилистики. Цель данной статьи стилистический анализ политических комментариев к постам Терезы Мэй в социальной сети «Twitter» и выявление эмоциональной детерминированности электората в отношении к её персоне.

Ключевые слова: Әискурс, политический Интернет-дискурс, комментарий, сочиальная сеть, стилистические средства, Twitter, Тереза Мэй.

DOI 10.18522/1995-0640-2020-1-77-84

Вульфович Борис Григорьевич - аспирант кафедры английской филологии факультета романо-германской филологии Кубанского государственного университета

Тел.: 8-928-846-80-91

E-mail: justb8888@gmail.com

(C) Вульфович Б.Г., 2020.
Тотальная компьютеризация и расширение возможностей доступа в Интернет в значительной степени позволили увеличить число пользователей всемирной паутины. Отличительной чертой подобного рода общения является двусторонность - потенциальное взаимное общение с адресатом, который был доступен только в одностороннем порядке. «До появления интернета массовая коммуникация была в большей мере однонаправленной с точки зрения адресата, с появлением интернета коммуникация стала интерактивной, двусторонней < ..> зависящей от потребностей, целей и задач необходимой коммуникативной деятельности» [Ахренова, 2018, с. 35].

Наша статья относится к сфере политического дискурса, который активно реализуется в среде всемирной паутины: «глобальная сеть тоже играет свою роль в осуществлении политической коммуникации. Так, практически у каждого политического деятеля есть свой сайт, на котором через опцию обратной связи можно обратиться к политику; или даже страница в социальной сети, а также блог» [Уварова, 2018, с. 18].

Поскольку предметом нашего исследования является именно лингвистическая сторона вопроса, то в работе мы будем опираться на определение А.П. Чудинова: политическая лингвистика - «новая для России наука, возникшая на пересечении лингвистики с политологией и учитывающая также достижения этнологии, социальной психологии, социологии и других гуманитарных наук» [Чудинов, 2006, с. 8]. 
Исходя из задач работы считаем необходимым расширить рамки термина «политическая лингвистика» до понятия «политическая медиалингвистика»: «новая лингвистическая дисциплина, соединение политической лингвистики и медиалингвистики. В действительности же политическая медиалингвистика - дисциплина на стыке лингвистики, политологии, медиалогии, когнитологии, философии и социологии» (Цит. по: [Фу, 2019, с. 16]), в то время как сама медиалингвистика обозначает любой вид языковой деятельность, воплощённый посредством сети Интернет.

В рамках данной статьи мы рассматриваем стилистическую сторону политического Интернет-дискурса, а именно категорию эмотивности, заключённую в Интернет-комментариях к постам Терезы Мэй в социальной сети «Twitter». В.И. Шаховский под эмоциями понимает «особую форму отношения человека к явлениям действительности, обусловленную их соответствием/несоответствием потребностям человека» [Шаховский, 1990].

Таким образом, нами будет проанализирован эмоциональный посыл, заложенный и реализованный стилистическими средствами разных уровней в комментариях к постам Терезы Мэй в социальной сети «Twitter».

Целью статьи является анализ стилистическиж особенностей политического Интернет-дискурса, реализованного в комментариях к постам Терезы Мэй по наиболее волнующим общественность событиям.

В связи с переходом языкознания в антропоцентрическую парадигму, всё большее внимание уделяется человеку. Данная научная парадигма наряду с активным внедрением компьютерных технологий в повседневную жизнь стала предметом исследований многих учёных разных областей: психологов, социологов и др. (А.А. Леонтьев, А.Р. Лурия, А.А. Радугин, Э. Тоффлер, Е.Б. Шестопал и др.).

Поскольку на данный момент коммуникативные акты всё чаще реализуются посредством сети Интернет, многие учёные стали акцентировать своё внимание на языковых средствах, используемых людьми непосредственно в Интернет-общении.

Так, вопросами политической лингвистики и её актуализацией в Интернет-среде занимается А.П. Чудинов [Чудинов, 2004]; Н.A. Ахренова изучает стилистические особенности языка Интернета [Ахренова, 2018]; вопросы хэштегов в Интернет-пространстве рассматривают В.В. Катермина, Н.А. Рябченко, О.П. Малышева и А.А. Гнедаш [Рябченко с соавт., 2018].

Сам политический дискурс также рассматривается многими исследователями (О.П. Акинина [2010], А.Н. Баранов [2000], М.В. Гаврилова [2013], В.Г. Перцева [2017], А.П. Чудинов [2004], и др.).

У. Анна [2019], Н.Г. Асмус [2014], Т.В. Семёнова [2019], И.Г. Сидорова [2011], Alice Bodoc [2018] и др. в своих работах рассматривают специфику политического Интернет-дискурса. 
Таким образом, данный вопрос актуален на сегодняшний день и является перспективным направлением для дальнейших исследований и углубления теоретической базы. В работе использовались следующие методы: описательный и стилистический анализ, метод частичной выборки. Материал для исследования отбирался методом частичной выборки, а сами стилистические явления были классифицированы по следующим уровням: графический, фонетический, морфологический, лексический, синтаксический. Всего нами было рассмотрены восемь постов и проанализирован 131 комментарий. Авторская пунктуация сохранена.

\section{Графический уровень}

Как правило, стилистические приёмы данного уровня служат для привлечения внимания читателя через зрительный канал связи. Это могут быть авторские знаки препинания (точки, запятые, тире), заглавные буквы, отсутствие знаков препинания и др. Прокомментируем комментарий: «and there is many smes destroyed by Lloyds bsu and RBS grg. regulate commercial loans and save a life today». Предложение начинается со строчной буквы, что нарушает грамматические нормы, однако в то же время является отличительной чертой Интернет-комментария. На примере этого же комментария отметим тенденцию к аграмматизму: «Характерной чертой пунктуации языка интернета является тенденция к аграмматизму, т. е. отклонению от пунктуационных стандартов, считающихся литературной нормой языка, со стороны автора текста» [Ахренова, 2018, с. 140 - 141]. Описываемое явление наглядно представлено в данном комментарии: помимо уже указанного нами начала предложения, мы находим точку, стоящую на отдалении от слова перед ней.

Ещё один фонетический стилистический приём, который можно отметить в данном комментарии - капитализация, используемая для создания в данном комментарии эмфазы и логического ударения (в конкретном случае на глаголе "to be" в форме 3 лица множественного числа), и желании подчеркнуть, что именно Тереза Мэй несёт ответственность за данную ситуацию: «целые слова могут быть набраны большими буквами и выделяются как произносимыми с особой эмфазой или особенно громко» [Арнольд, 1973, с. 287].

Использование необъективного количества знаков препинания также привлекает внимание на графическом уровне: «нрросrite!!». Количество восклицательных знаков указывает на эмоциональную отвлечённость его автора или же намеренное, нестандартное эмфатическое выделение слова.

\section{Фонетический уровень}

Данный уровень является самым немногочисленным по сравнению с другими и может быть представлен следующими приёмами: звукоподражание, звукопись (аллитерация/ассонанс), рифма, ритм, звуковые повторы (анафора/эпифора) и др.

Среди данных явлений нами была выявлена только паронимическая аттракция - намеренное сближение слов, имеющих звуковое сходство: «Oh, and I hear you've gone and bought yourself a nice little retreat 
somewhere while we're left to struggle post BrexSHIT. Is that so?». Замена нескольких букв в слове «Brexit» привела к ироничному выражению мнения читателя о происходящих в стране событиях.

\section{Морфологический уровень}

Стилистические средства на морфолоигческом уровне реализуются путём изменения форм слова и его грамматических категорий. В эту группу могут входить: категория времени (например, использование настоящих времён вместо прошедших или использование the Present Continuous для выражения раздражения), неформальные формы служебных глаголов (ain't), стилистическое применение категории модальности и др.

Говоря об грамматических отклонениях, отметим неправильное употребление оборота there is/are в следующем комментарии, поскольку сокращение «SME» используется во множественном числе: «and there is many smes destroyed by Lloyds bsu and RBS grg.regulate commercial loans and save a life today».

Использование пассивного залога также применяется авторами комментариев для определённого манипулятивного воздействия на аудиторию, так как частота употребления пассивных конструкций в английском языке гораздо выше, чем в русском: «At the morphosyntactic and pragmatic levels of language, speech manipulation is carried out by means of special tools/methods, such as passivization, topicalization, nominalization, modality, and elliptic constructions» [Bodoc, 2018, p. 61]. Примером подобного применения пассивного залога может служить следующий комментарий: «Whereas it is of paramount importance for the world to fight terror. It is much more important that we prevent the Tony Blair's and the George Bushes et al from sowing the seeds of hatred in faraway lands. Responsibility has to be ascribed to the root cause». По мнению автора, «ответственность» должна стать «корневой причиной»; в данном примере пассивный залог использован для введения некого «предписания свыше», тем самым, подчёркивая свой формальный характер.

Категория модальности присутствует в примере «it must be so good to live in your universe». Глагол «must» употреблён в функции дедукции, однако он применяется для создания ироничного эффекта, так как, на самом деле, по мнению автора, «жизнь во вселенной Терезы Мэй» не так уж и хороша.

Употребление вспомогательного глагола в повествовательном предложении также является средством выражения эмоциональной экспрессии и усиления степени высказывания: «You do talk rubbish, Mrs May».

\section{Лексический уровень}

В данную группу входит достаточно широкий ряд стилистических приёмов: метафора, метонимия, синекдоха, ирония, полисемия, игра слов, зевгма, междометие, эпитет, оксюморон и проч.

Эпитеты активно употребляются комментаторами для выражения экспрессии их высказывания: «Наиболее ярким показателем политического отношения к международным проблемам является эпитет, т.е. 
прилагательное, которое передает качественную или относительную семантику, в которой отчетливо проявляется политическая оценка и через нее позиция говорящего» [У Анна, 2019, с. 53]. Например, эпитеты «disheartened» и «embarrassed» в комментарии «Yоu have destroyed all illusions we may have had that we live in a Democracy. I heave never felt so disheartened or embarrassed to be British. You have been the worst Prime Minister in recent history. Resign» выражают негативную оценку политических действий Терезы Мэй.

Более того, метафора присутствует в комментариях в отношении Брексит, которая сопоставляется с «ночным кошмаром всей страны»: «You're so hopelessly mad that you're planning to lease car ferries to ship food and medicine in when your deluded Brexit dreams become the entire country's nightmare! RESIGN!».

Авторы комментариев прибегают к использованию цитат. Помимо цитат непосредственно исходного поста («The "balanced approach to the economy" argument went out of the window when the government decided to proceed with Brexit without first scoping out the detail E likely economic damage, which is already catastrophic. The Conservatives won't have any money left for a tax cut»), авторы склонны привлекать дополнительные источники, например, Библию: «Yeah coz Treeza's dead Christian and shizzle. It's like when Jesus said (in the bible.probably) "Bollocks to the povs, spend 950 sovs on kecks madeth of leather and leopard skin print shoes and matching handbag innit blood." And so it was done». Это свидетельствует о различных ассоциациях и параллелях, которые авторы хотят показать.

\section{Синтаксические средства}

Стилистические приёмы на уровне синтаксиса довольно часто используются в Интернет-текстах. Среди таких приёмов можно выделить инверсию, обособление, транспозицию и проч.

Риторические вопросы часто встречаются в комментариях и призывают заострить внимание на проблеме, заявленной в комментарии, и усилить эмотивность самого комментария: «Don't forget those forced into prostitution by your UC! Why did you refuse to make your investigation into UC public? Why hide it away? The subliminal message is that it showes it is flawed!».

Явление транспозиции представлено в следующем примере: «I would be happier if you stopped lying to us and manipulating figures. Schools are under funded, NHS is in tatters, more people living on the streets, the police can no longer afford to do their jobs, but still you say you are taking Britain forwards? Forwards into what?». В данном примере утвердительные по форме предложения используются как вопросы, так как автор хочет показать, что он уже догадывается о том, каков будет ответ, и это ему не безразлично. Такая транспозиция характерна для разговорной речи и насыщает вопросы иронией или даже сарказмом.

Инверсия: «Never in my 40 years service has moral been so low»-акцентирует внимание на том, что подобных описываемых случаев в личном опыте автора ещё не было. 
Таким образом, на основе проведённого нами стилистического анализа, мы можем прийти к определённым выводам.

Отношение британского социума к Терезе Мэй крайне негативное. Большое количество средств экспрессивности свидетельствует об эмоциональной встревоженности общества.

В анализируемом материале преобладают эмоциональные комментарии, представленные на всех языковых уровнях (графическом, фонетическом, морфологическом, лексическом, синтаксическом), что показывает не только общую картину тревоги, но и подчёркивает характер комментаторов и мотивы его проявления.

Получив свободу комментирования в Интернет-пространстве, многие пользователи начали активно проявлять свои эмоции: комментарии подчёркивают, с одной стороны, анонимность и безнаказанность авторов комментариев, а с другой - несмотря на чопорность английского общества - их внутреннюю заинтересованность в будущем своей страны.

\section{Литература}

Акинина О.П. Лингво-дискурсивные особенности публичных выступлений (на материале речей политических лидеров США и Великобритании XXXXI веков): дис.... канд. филол. наук. Волгоград, 2010. 208 с. (Волгоградский гос. пед. ун-т)

Арнольд И.В. Стилистика современного английского языка: учеб. пособие для студентов фак. и ин-тов иностр. яз. Л.: Просвещение, 1973. 303 с.

Асмус Н.Г. Когнитивные основы виртуального дискурса // Когнитивные исследования языка. Общероссийская общественная организация «Российская ассоциация лингвистов-когнитологов» (Тамбов), 2014. № 18. С. 590 - 593.

Ахренова Н.А. Доминанты современной Интернет-лингвистики: дис.... д-р филол. наук. Мытищи, 2018. 363 с. (Московский гос. обл. ун-т)

Баранов А.Н. Политика как диалог // Полис. Политические исследования. M., 2000. № 4. C. 24.

Гаврилова М.В. Когнитивные исследования политического дискурса // Дискурс-Пи. / Институт философии и права УрО РАН (Екатеринбург), 2013. № 3 (13). C. 116 - 117.

Периева В.Г. Англоязычные словари языка политиков и философов (на материале словарей цитат и пословиц): дис.... канд. филол. наук. Иваново, 2017. 229 с. (Ивановский гос. ун-т)

Рябченко Н.А., Катермина В.В., Гнедаш А.А., Малышева О.П. Политический контент социальных движений в online-пространстве современных государств: методология анализа и исследовательская практика // Южно-российский журн. социальных наук. 2018. Т. 19, № 3. С. 139 - 162.

Семёнова T.B. Особенности языковой репрезентации индивидуально-авторской картины мира в поэтическом дискурс (на материале свободного стиха У.Х. Одена): дис.... канд. филол. наук. Владикавказ:, 2019. 190 с. (Северо-Осетинский гос. ун-т им. К.Л. Хетагурова).

Сидорова И.Г. Коммуникативно-прагматические характеристики персональных и интерперсональных жанров Интернет-дискурса // Вестн. Волгоградского гос. ун-та. Серия 2: Языкознание. 2011. № 2 (14). С. 154 - 159.

У Анна. Стилистические и лингво-прагматические характеристики публичной речи политических лидеров России конца XX и начала XXI веков: 
дис.... канд. филол. наук. М., 2019. 202 с. (Гос. ин-т русского языка им. А.С. Пушкина).

Уварова E.A. Типологические характеристики новостного веб-сайта как поликодового текста (на примере информационного портала «The Onion»): дис.... канд. филол. наук. М., 2018. 227 с. (Московский пед. гос. ун-т).

Фу Хэчжень. Политическая медиалингвистика: референциальные и аксиологические аспекты новостных статей современной российской прессы: дис.... канд. филол. наук. Волгоград, 2019. 265 с. (Волгоградский гос. соц.-пед. ун-т).

Чудинов А.П. Политическая лингвистика: учеб. пособие. М.: Флинта, Наука. 2006. 254 с.

Чудинов А.П. Когнитивно-дискурсивное исследование политической метафоры // Вопросы когнитивной лингвистики. Общероссийская общественная организация «Российская ассоциация лингвистов-когнитологов» (Тамбов), 2004. № 1. С. $91-105$.

Шаховский В.И. Эмотивная семантика слова как коммуникативная сущность // Коммуникативные аспекты значения: сб. статей. Волгоград: Волгр. пед. ин-т, 1990. С. 29 - 40.

Bodoc Alice. Linguistic instruments employed in political discourses. Manipulation tools or expressions of human universal behaviour? // Bulletin of the Transilvania University of Braşov. Series IV: Philology and Cultural Studies. 2018. Vol. 11 (60), no. 2, pp. $49-70$.

\section{References}

Akinina O.P. Lingvo-diskursionyye osobennosti publichnykh vystupleniy (na materiale rechey politicheskikh liderov SShA $i$ Velikobritanii XX-XXI vekov): dis.... kand. filol. nauk. Volgograd, 2010. 208 p. (In Russian).

Arnol'd I.V. Stilistika sovremennogo angliyskogo yazyka: ucheb. posobiye dlya studentov fak. i in-tov inostr. yaz. L., Prosveshcheniye, 1973. 303 p. (In Russian).

Asmus N.G. Kognitivnyye osnovy` virtual'nogo diskursa. Kognitionyye issledovaniya yazyka. Obshherossiyskaya obshhestvennaya organizatsiya «Rossijskaya assotsiatsiya lingvistov-kognitologov» (Tambov), 2014, no. 18, pp. 590-593. (In Russian).

Akhrenova N.A. Dominanty' sovremennoy Internet-lingzistiki: dis... $d$-r filol. nauk. Mytishchi, 2018. 363 p. (In Russian).

Baranov A.N. Politika kak dialog. Polis. Politicheskiye issledovaniya, M., 2000, no. 4, p. 24. (In Russian).

Gavrilova M.V. Kognitivnyye issledovaniya politicheskogo diskursa. DiskursPi. Institut filosofii i prava UrO RAN (Ekaterinburg), 2013, no. 3 (13), pp. 116-117. (In Russian).

Pertseva V.G. Angloyazychnyye slovari yazyka politikov i filosofov (na materiale slovarey tsitat i poslovits): dis... kand. filol. nauk. Ivanovo, 2017. 229 p. (In Russian).

Ryabchenko N.A., Katermina V.V., Gnedash A.A., Malysheva O.P. Politicheskiy kontent sotsial'nykh dvizheniy $\mathrm{v}$ online-prostranstve sovremennykh gosudarstv: metodologiya analiza i issledovatel'skaya praktika. Yuzhno-rossiyskiy zhurnal sotsialnykh nauk, 2018, vol. 19, no. 3, pp. 139-162. (In Russian).

Semyonova T.V. Osobennosti yazykovoy reprezentatsii individual no-avtorskoy kartiny mira v poehticheskom diskurse (na materiale svobodnogo stikha U.Kh. Odena): dis.... kand. filol. nauk. Vladikavkaz, 2019. 190 p. (In Russian).

Sidorova I.G. Kommunikativno-pragmaticheskiye kharakteristiki personal’nykh i interpesonal’nykh zhanrov Internet-diskursa. Vestn. Volgogradskogo 
gos. un-ta. Seriya 2: Yazykoznaniye. Volgogradskiy gos. un-t (Volgograd), 2011, no. 2 (14), pp. 154-159. (In Russian).

U Anna. Stilisticheskiye $i$ lingvo-pragmaticheskiye kharakteristiki publichnoy rechi politicheskikh liderov Rossii kontsa XX $i$ nachala XXI vekov: dis.... kand. filol. nauk. M., 2019. 202 p. (In Russian).

Uvarova E.A. Tipologicheskiye kharakteristiki novostnogo veb-sayta kak polikodovogo teksta (na primere informatsionnogo portala «The Onion»): dis.... kand. filol. nauk. M., 2018. 227 p. (In Russian).

$\mathrm{Fu}$ Khe`chzhen`. Politicheskaya medialingvistika: referentsial nyye $i$ aksiologicheskiye aspekty novostnykh statey sovremennoy rossiyskoy pressy: dis.... kand. filol. nauk. Volgograd, 2019. 265 p. (In Russian).

Chudinov A.P. Politicheskaya lingvistika: ucheb. posobiye. M., Izd-vo Flinta, Nauka. 2006. 254 p. (In Russian).

Chudinov A.P. Kognitivno-diskursivnoye issledovaniye politicheskoy metafory. Voprosy kognitionoy lingzistiki. Obshcherossiyskaya obshchestvennaya organizaciya «Rossiyskaya assotsiatsiya lingvistov-kognitologov» (Tambov), 2004, no. 1, pp. 91105. (In Russian).

Shakhovskiy V.I. Ehmotivnaya semantika slova kak kommunikativnaya sushchnost'. Kommunikationyye aspekty znacheniya. Volgograd: Volgr. ped. in-t, 1990. P. 29-40. (In Russian).

Bodoc Alice. Linguistic instruments employed in political discourses. Manipulation tools or expressions of human universal behaviour? Bulletin of the Transilvania University of Brașov Series IV: Philology and Cultural Studies, 2018, vol. 11 (60), no. 2, pp. 49-70. (In English).

Boris G. Vulfovich (Krasnodar, Russian Federation)

Stylistic Peculiarities of the Political Internet-Discourse (Based on Comments to Theresa May's Posts in Twitter)

Modern political discourse has obtained a new level, i.e. bilateral due to the Internet. This feature of this social network lets a user make a comment to any post written on the page and, what is more, there is a high possibility that a person addressed will read it and answer it. As a comment is considered to be an individual's speech act it can be rendered from stylistics' point of view. Implying stylistics into speech can be explained by an attempt to cause a certain emotional reaction of a person. The given article deals with the stylistic analysis of such comments to Theresa May's posts in "Twitter" and subsequent determination of the emotive state of the readers.

Key words: discourse, political Internet-discourse, comment, social network, stylistic means, Twitter, Theresa May.

Boris G. Vulfovich - post-graduate student. Kuban State University. English Philology dpt. Phone: 8-928-846-80-91; e-mail: justb8888@gmail. com 